\title{
Solitary Osseous Plasmacytoma of a Lumbar Vertebrae with Systemic Involvement in a Dog
}

\author{
Bruna Voltolin de Sena', Leonardo Lima Gorza', Alice Correa Rassele Merísio', Mayra Cunha Flecher', \\ Ayisa Rodrigues de Oliveira² \& Rodrigo dos Santos Horta'
}

\begin{abstract}
Background: Myeloma-related disorders are characterized by proliferation of neoplastic plasma cell or immature immunoglobulin secreting B-lymphocytes, and include multiple myeloma, M-macroglobulinemia and extra-medullary plasmacytoma (cutaneous or extra-cutaneous). Solitary osseous plasmacytoma (SOP) is considered an unique entity among extra-medullary extra-cutaneous plasmacytoma. It is an unusual neoplasia in dogs, predominantly found in middle-aged to older animals, with a higher incidence in bones of axial skeleton. Dogs with vertebral SOP present neurological signs related to spinal cord compression, but progression to multiple myeloma is related to a poor outcome. As in humans, progression to multiple myeloma occurs in most cases, although it may take months or years from its initial presentation. SOP's biological behaviour, incidence and prognostic are rarely documented. Chemotherapy with melphalan and prednisolone represent the most used protocol for multiple myeloma. However, in SOP, the combination of chemotherapy with local approaches is controversial before the evidence of systemic disease. This paper aims at reporting a case of SOP in a lumbar vertebrae of a dog, with systemic involvement.

Case: A 11-year old male mixed breed dog was attended presenting muscle weakness, lethargy, anorexia, adipsia and intense pain manifestation. The dog also presented multiple skin nodules, previously diagnosed as a plasmacytoma, through cytology. The dog's poor clinical condition and aggressive temper, associated with suspicious of an advanced myelomarelated disorder, resulted in the decision for humanized euthanasia. At necropsy, a pale, friable and hemorrhagic mass was identified on the L3 lumbar vertebrae, associated with an osteolytic bone lesion and spinal cord compression. Histopathological analyses revealed proliferation of plasma cells, with pale perinuclear halo, moderate cellular pleomorphism, 10 binucleated cells and 10 mitotic figures per 10 high power fields, compatible with extramedullary plasmacytoma of the mature type, in the lumbar vertebrae (SOP). It was also seen myeloma-related lesions in the skin and subcutaneous, prostate, heart, superficial mandibular and axillary lymph nodes

Discussion: Solitary osseous plasmacytoma is a myeloma-related disorder rarely reported in dogs. Its biological behaviour is poorly characterized, however progression for multiple myeloma is common in humans and dogs, and it is related to a poor outcome. As the present report, systemic progression of SOP has been previously described and although an overt bone marrow infiltration was not detected, such possibility can not be excluded, once multiple myeloma distribution in the bone marrow is often multifocal. Although chemotherapy is the treatment of choice for multiple myeloma, its indication for SOP is conditioned to the evidence of systemic disease. It might delay tumour progression, but its early implementation may favor the selection of resistant neoplastic clones, making it ineffective when progression to multiple myeloma occurs. In humans radiotherapy is the treatment of choice for SOP, however it may be indicated in association to surgery. A retrospective study showed a higher survival rate in patients with SOP in the axial skeleton, which received surgical treatment combined with radiotherapy, if compared to those treated with surgery or radiotherapy alone. Decision for euthanasia was made based on the suspicious of advanced myeloma-related disorder, patient's medical condition and aggressive temper, which limited diagnostic investigation and treatment.
\end{abstract}

Keywords: neoplasia, plasma cells, multiple myeloma, histopathology, prognosis.

DOI: $10.22456 / 1679-9216.90149$

Accepted: 24 January 2019

Published: 7 February 2019 
B.V. Sena, L.L. Gorza, A.C.R. Merísio, et al. 2019. Solitary Osseous Plasmacytoma of a Lumbar Vertebrae with Systemic

\section{INTRODUCTION}

Myeloma-related disorders are characterized by proliferation of neoplastic plasma cell or immature immunoglobulin secreting B-lymphocytes, and include multiple myeloma, M-macroglobulinemia and extra-medullary plasmacytoma (cutaneous or extra-cutaneous). Nevertheless, the solitary osseous plasmacytoma (SOP) is described, by some authors, as a specific pathology among the extra-cutaneous / extra-medullary plasmacytoma $[5,18]$. In humans, SOP represent $3 \%$ of all cases of myeloma-related disorders [9], and have been described infrequently in dogs, affecting mostly middle-aged to older animals [17], with a higher incidence in the axial skeleton $[14,15,17]$. As in humans, progression to multiple myeloma occurs in most cases, although it may take months or years from its initial presentation [17].

Treatment decision is based on affected site, extension and systemic involvement [18]. Surgery may be indicated prior to radiotherapy for spinal cord decompression and stabilization [17]. This association is also recommended in cases whose injury resulted in unstable long-bones fractures [21]. Nevertheless, radiotherapy may be used as a single treatment, in dogs with stable long-bones fractures or vertebral involvement, without spinal cord compression [17]. Even when local control is successful, most of these patients will progress to multiple myeloma $[12,17]$. Chemotherapy with melphalan and prednisolone represent the most used protocol for multiple myeloma [18]. However, in SOP, the combination of chemotherapy with local approaches is controversial before the evidence of systemic disease [17,22]. In humans, chemotherapy doesn't prevent the progression of SOP to multiple myeloma, but can delay it [4].

This paper aims at reporting a case of a SOP in a lumbar vertebrae of a dog, with systemic involvement, including skin, prostate, hearth and lymph nodes, in order to increase information about occurrence and biological behaviour of this neoplasm.

\section{CASE}

A 11-year-old male mixed breed dog was attended at the Veterinary Hospital Prof. Ricardo Alexandre Hippler, at University of Vila Velha- ES, Brazil, with a history of muscle weakness, at approximately one month ago, lethargy, anorexia, adipsia and intense pain manifestation. The dog also presented multiple skin nodules, first identified one month ago and diagnosed as a plasmacytoma, through cytology.
At physical examination, patient showed mild dehydration, and multiple nodular lesions measuring 1 to $2 \mathrm{~cm}$ (Figure 1), in the neck, pre-scapular and perianal regions, besides allodynia and reluctance to move. Patient's aggressive temper prevented a complete neurological examination.

A complete blood count and biochemical analysis (total proteins and fractions, urea, creatinine, alanine aminotransferase, alkaline phosphatase, calcium) was perfomed and it was unremarkable. Abdominal ultrasound also did not revealed any abnormality. Nodular lesions of the neck and perianal regions were re-assessed through cytology, and an excisional biopsy was perfomed in a $2 \mathrm{~cm}$ nodule in the cervical region.

Cytology revealed the presence of plasma cells with coarse chromatin, indistinct nuclei, considerable anisokaryosis and single nuclear pleomorphism, compatible with plasmacytoma. Histopathology showed predominance of oval-shaped plasma cell with eosinophilic cytoplasm, round eccentric nucleus, moderate cellular pleomorphism, prominent anisocytosis and clumping chromatin. Giant cells were not observed but five mitotic figures were counted in 10 high powerfields, characterizing an extramedullary plasmacytoma of the mature type [16]. A bone marrow sample was collected from the sternum and showed no increase of plasma cells (less than 3\%) or cellular atypia.

Due to the patient's medical condition and suspicious of a myeloma-related disorder, the dog was hospitalized for pain control and replacement of dehydration deficit. Hydrocortisone ${ }^{1}(5 \mathrm{mg} / \mathrm{kg})$ and methadone $^{2}(0.3 \mathrm{mg} / \mathrm{kg})$, were intravenously administered, every $4 \mathrm{~h}$. After $12 \mathrm{~h}$ the patient was still showing signs of pain and resistance to physical examination. A new analgesia protocol was performed, with continuous infusion of morphine $\mathrm{e}^{3}(0.2 \mathrm{mg} / \mathrm{kg} / \mathrm{h})$ and ketamine ${ }^{4}$ $10 \%(0.6 \mathrm{mg} / \mathrm{kg} / \mathrm{h})$. This protocol was effective in promoting patient's comfort and pain relief, however, humanized euthanasia was elected, with the owner's consent, due to the dog's aggressive temper, associated with difficulty in administration of oral medication and poor clinical condition, and it was performed before radiographs, protein electrophoresis and Bence-Jones proteinuria could be investigated.

At necropsy, a pale, friable and hemorrhagic mass was identified on the L3 lumbar vertebrae, associated with an osteolytic bone lesion and spinal cord compression (Figure 2A). The histopathological slides were 


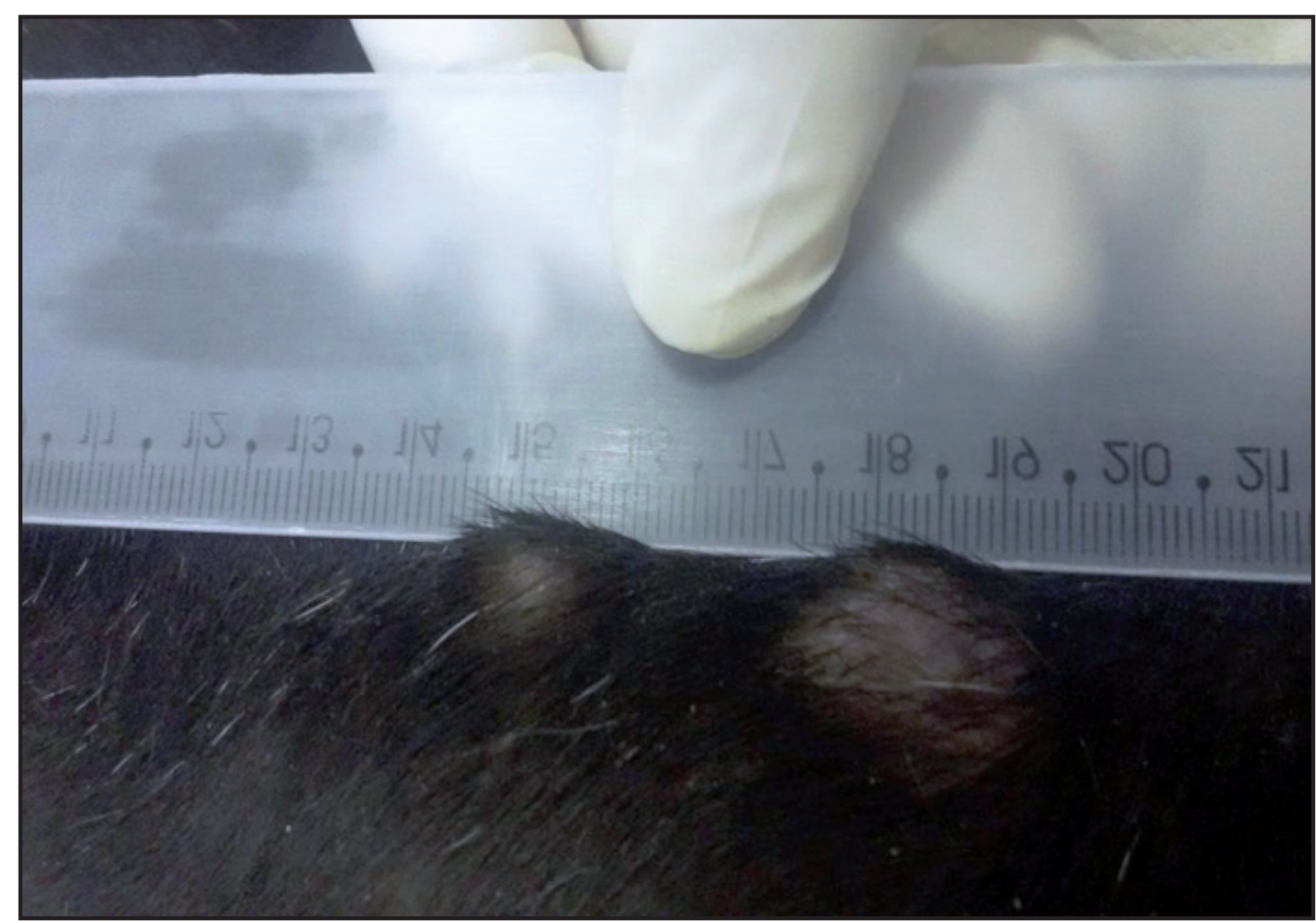

Figure 1. Multiple skin nodules of plasma cell proliferation measuring one to two centimeters in a 11-year-old mixed breed dog with solitary osseous plasmacytoma.

stained with hematoxylin and eosin, which revealed proliferation of plasma cells, with pale perinuclear halo, moderate cellular pleomorphism, 10 binucleated cells and 10 mitotic figures per 10 high power fields. It was also seen myeloma-related lesions in the skin and subcutaneous (Figure 2B), prostate (Figure 2C), heart (Figure 2D), superficial mandibular and axillary lymph nodes. Based on the clinical and anatomopathological features, the diagnosis was defined as an extramedullary plasmacytoma of the mature type [16], with probably onset in lumbar vertebrae (SOP) and metastasis to the skin and subcutaneous, prostate, heart and superficial mandibular and axillary lymph nodes.

\section{DISCUSSION}

SOP is a rare malignancy in humans and dogs that mainly affects bones of the axial skeleton such as mandible [1,15], vertebrae [14,22] and ribs [6], but it might as well occur in the femur [11] and tibia [10], in appendicular skeleton. Affected dogs are usually middle-aged to older, as described in this case.
Dogs with vertebral SOP may present neurological abnormalities related to spinal cord compression, which includes pain, paresis/paralysis, sensibility loss and Schiff-Sherrington syndrome [17], nevertheless although pain manifestation was evident in the reported case, semiological characterization was limited by the dog's aggressive temper.

According to the histophatological features, extramedullary plasmacytoma can be classified into 5 diferent subtypes, presented in the Table 1: mature, cleaved, hyaline, asynchronous and polymorphous-blastic type. Although this classification has not shown relevance in the prognosis [16], it was used in the present study, in order to contribute to the current knowledge of this uncommon disease. In the present report, histopathological findings of the vertebral tumour were compatible with the extramedullary plasmacytoma of the mature type.

SOP's biological behaviour remains poorly characterized. In humans $65-84 \%$ of the cases progress to multiple myeloma in 15 years resulting in poor prognosis $[7,8]$. A poor outcome for systemic involve- 


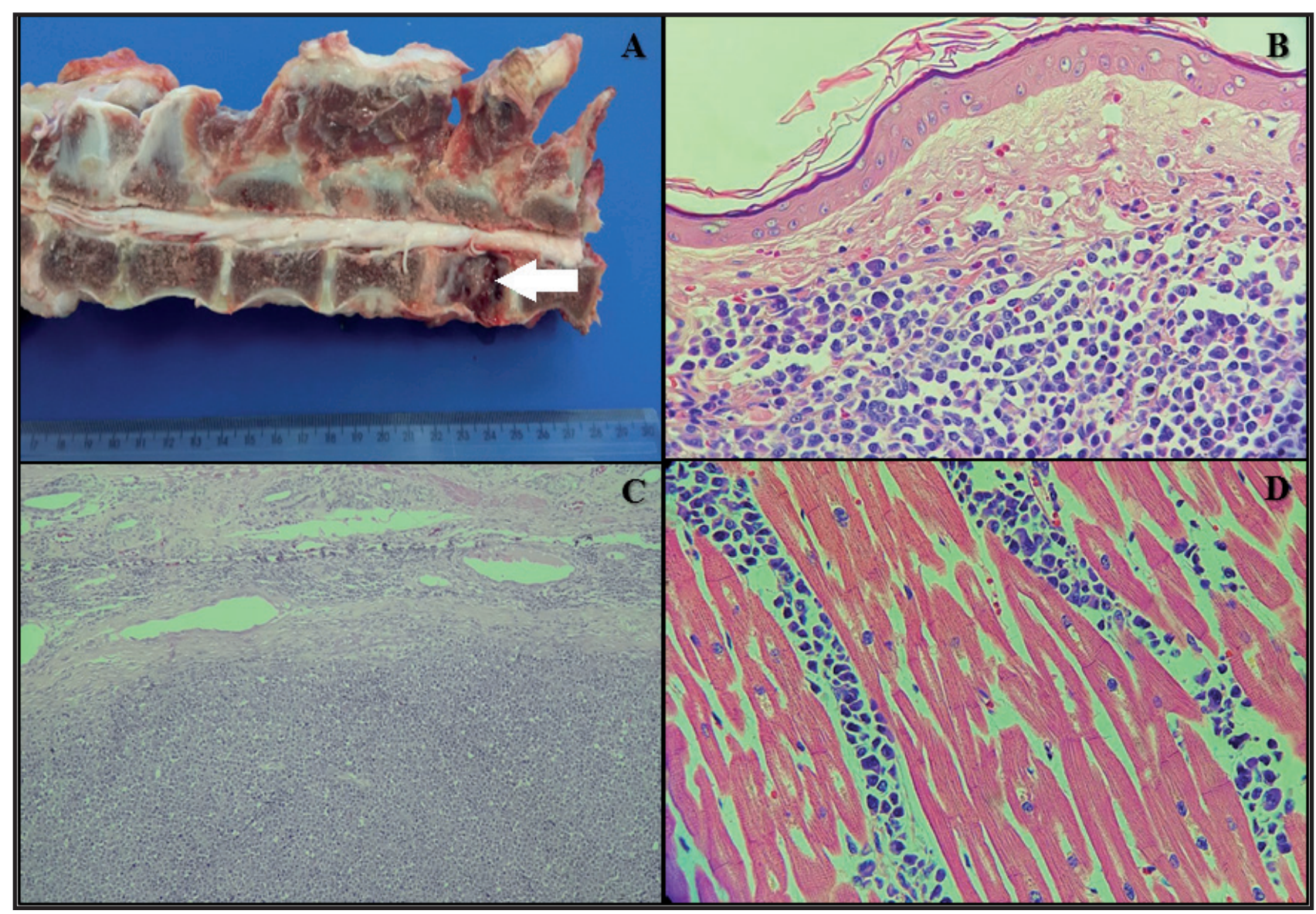

Figure 2. Anatomopathological features of a 11-year old mixed breed dog. A- L3 lumbar vertebrae: solitary osseous plasmacytoma associated with an osteolytic bone lesion and spinal cord compression. B- Skin: Plasma cell proliferation on skin nodules [H\&E, 40x]. C- Prostate: Plasma cell infiltrative [H\&E, 10x]. D- Heart: Plasma cell infiltrative within myocardial fibers [H\&E, 40x].

Table 1. Histopathological features for grading of the canine extramedullary plasmacytomas.

\begin{tabular}{|c|c|c|c|}
\hline Histopathologic type & Nuclear morphology & Number of giant cells & Cytoplasm in the HE stain \\
\hline Mature & Oval-shaped & Small number & $\begin{array}{l}\text { Numerous cytoplasmic } \\
\text { vacuoles or an eosinophilic } \\
\text { fine-grained cytoplasm }\end{array}$ \\
\hline Hyaline & Sickle-shaped & Small number & $\begin{array}{l}\text { Eosinophlic and centrally } \\
\text { transparent }\end{array}$ \\
\hline Cleaved & Indented and cleaved & Numerous & Scarce cytoplasm \\
\hline Asynchronous & Blastic & Numerous & $\begin{array}{c}\text { Eosinophilic and vacuolar } \\
\text { cytoplasm }\end{array}$ \\
\hline Polymorphous-blastic & More or less blastic & Numerous & $\begin{array}{c}\text { Generally has eosinophilic, } \\
\text { vacuolar cytoplasm }\end{array}$ \\
\hline
\end{tabular}

ment was also demonstrated in dogs, in a retrospective study that included medical records of eight dogs with neurological abnormalities compatible to spinal cord compression, and histopathological diagnosis of SOP in the lumbar vertebrae [17]. In this study, six dogs presented other sites of plasma cell proliferation besides the vertebrae, including liver, spleen, kidney, mesenteric lymph nodes and oral mucosa. Neoplastic involvement of the bone marrow was detected in only two of these dogs and an overt bone marrow infiltration was also not detected in the reported case. Nevertheless multiple myeloma distribution in the bone marrow is often multifocal and plasma cell values below $10 \%$ do not exclude the possibility of such involvement [2]. In the present report, it was not possible to precise the time of disease development and onset of neurologi- 
cal signs, but the disease was present for at least one month, when skin nodules of plasma cell proliferation first appeared.

In humans radiotherapy is the treatment of choice, however it is indicated in association to surgery whenever spinal stabilization and/or spinal cord decompression are necessary [6,19]. A retrospective study showed a higher survival rate in patients with SOP in the axial skeleton, which received surgical treatment combined with radiotherapy $(70.5 \%)$, if compared to those treated with surgery alone $(46.4 \%)$ or radiotherapy alone $(61.5 \%)$ [20].

Chemotherapy is the treatment of choice for multiple myeloma however its indication for SOP is conditioned to the evidence of systemic disease. Although it might delay its progression, early implementation of chemotherapy may favor the selection of resistant neoplastic clones, making it ineffective when progression to multiple myeloma occurs [4]. Melphalan is the main drug used in management of multiple myeloma, and it can be orally administered to dogs in 2 different schemes: a continuous low-dose regimen $(0.1 \mathrm{mg} / \mathrm{kg}$ every $24 \mathrm{~h}$ for 10 days, followed by 0.05 $\mathrm{mg} / \mathrm{kg}$ every $24 \mathrm{~h}$ continuously) or a pulse-dosing regimen $\left(7 \mathrm{mg} / \mathrm{m}^{2}\right.$ every $24 \mathrm{~h}$ for 5 consecutive days, every 3 weeks). Treatment efficacy may be increased when melphalan is combined to oral prednisolone at a dosage of $0.5 \mathrm{mg} / \mathrm{kg}$ daily, in the 10 first days, followed by the same dose, in alternated days for more 60 days. Cyclophosphamide may be used in the first day of melphalan, at a dosage of $200 \mathrm{mg} / \mathrm{m}^{2}$, in order to achieve fast remission of clinical signs in patients with poor clinical condition, as well as a substitute to melphalan in the occurrence of thrombocytopenia after prolonged use. The median survival time is $\mathbf{5 4 0}$ days, and complete remission is seen in approximately $43 \%$ of cases, however $49 \%$ achieve partial remission [12].

In the reported case, the patient's aggressive behaviour and medical condition limited diagnostic investigation and medical treatment, and euthanasia was carefully chosen along with the owner. However, until the decision could be made, analgesia was attempted and the analgesic protocol with continuous infusion of morphine and ketamine, showed a remarkable efficacy, differing from the protocol performed in a different study, in which tramadol $(5 \mathrm{mg} / \mathrm{kg})$ and dipyrone (25 $\mathrm{mg} / \mathrm{kg}$ ) were administered every $8 \mathrm{~h}$, along with gabapentin $(5 \mathrm{mg} / \mathrm{kg})$ every $24 \mathrm{~h} \mathrm{[14].}$

\section{CONCLUSION}

This paper describes an unusual case of an extra-cutaneous extra-medullary plasmacytoma of the mature type, located in a lumbar vertebrae (SOP) of a dog with subsequent involvement of the skin and subcutaneous, prostate, heart, superficial mandibular and axillary lymph nodes. Analgesic protocol with continuous infusion of morphine and ketamine was effective in this case. The prognosis for SOP with systemic involvement seems poor, although it might be related to radiographical and histopathological features, presence of monoclonal hypergammaglobulinemia and Bence-Jones proteinuria, but this must be further investigated, alongside with surgical or medical treatment response.

\section{MANUFACTURERS}

${ }^{1}$ Novafarma Indústria Farmacêutica Ltda. Anápolis, GO, Brazil.

${ }^{2}$ Cristália Produtos Químicos Farmacêuticos Ltda. Itapira, SP, Brazil ${ }^{3}$ Hipolabor Farmacêutica Ltda. Sabará, MG, Brazil.

${ }^{4}$ Syntec do Brasil Ltda. Santana de Parnaíba, SP, Brazil.

Declaration of interest. The authors report no conflicts of interest. The authors alone are responsible for the content and writing of paper.

\section{REFERENCES}

1 Baad R., Kapse S.C., Rathod N., Sonawane K., Thete S.G. \& Kumar M.N. 2013. Plasmacytoma of the MandibleA Rare Entity. Journal of International Oral Health. 5(3): 97-101.

2 Bartl R., Frisch B., Fateh-Moghadam A., Kettner G., Jaeger K. \& Sommerfeld W. 1987. Histologic classification and staging of multiple myeloma. A retrospective and prospective study of 674 cases. American Journal of Clinical Pathology. 87(3): 342-355.

3 Dayisoylu E.H., Ceneli O.\& Coskunoglu E.Z. 2016. Solitary Plasmacytoma of the Mandible: An uncommon Entity. Iranian Red Crescent Medical Journal. 18(7): 1-5.

4 Ellis P.A. \& Colls B.M. 1992. Solitary Plasmocytoma of Bone: Clinical Features, Treatment and Survival. Hematological Oncology. 10(3-4): 207-211.

5 Fry M.M. \& Macgavin M.D. 2009. Medula óssea, células sanguíneas e sistema linfático. In: Macgavin M.D. \& Zachary J.F. (Eds). Bases da Patologia Veterinária. Rio de Janeiro: Saunders Elsevier, pp.802-803. 
6 Haser G.C., Su H.K., Pitman M.J. \& Khorsandi A.S. 2015. Extramedullary plasmacytoma of the cricoid cartilage with solitary plasmacytoma of the rib. American Journal of Otolaryngology. 36(4): 598-600.

7 Kilciksiz S., Celik O.K., Pak Y.D., Demiral A.N., Pehlivan M., Orhan O., Tokatti F., Agaoglu F., Zincircioglu B., Atasoy B.M., Ozseker N., Yersal O., Niang U. \& Haydaroglu. 2008. A Clinical and prognostic features of plasmacytomas: a multicenter study of Turkish Oncology Group- Sarcoma Working Party. American Journal of Hematology. 83(9): 702-707.

8 Knobel D., Zhouhair A., Tsang R.W., Poortmans P., Belkacémi Y., Bolla M., Oner F.D., Landmann C., Castelain B. \& Ozsahin M. 2006. Prognostic factors in solitary plasmacytoma of the bone: a multicenter Rare Cancer Network study. BMC Cancer. (118): 1-9.

9 Knowling M.A., Harwood A.R. \& Bergsagel D.E. 1983. Comparison of extramedullary plasmacytomas with solitary and multiple plasma cell tumors of bone. Journal of Clinical Oncology. 1(4): 255-262.

10 Kumar P., Sharma S.C., Saikia U.N., Kumar N., Vyas S. \& Angurana S.L. 2011. Solitary plasmacytoma of the proximal tíbia in an adolescente. Pediatric Blood \& Cancer. 56(1): 158-160.

11 Matar H.E., Mottram C. \& Gudena R. 2015. Proximal fêmur giant solitary plasmacytoma of boné: lessons learnt. Brazilian Medical Journal. 2015: 1-2.

12 Matus R.E., Leifer C.E., MacEwen E.G. \& Hurvitz A.I. 1986. Prognostic factors for multiple myeloma in the dog. Journal of the American Veterinary Medical Association. 188(11): 1288-1292.

13 Mendenhall W.M., Mendenhall C.M. \& Mendenhall N.P. 2003. Solitary plasmacytoma of bone and soft tissues. American Journal of Otolaryngology. 24(6): 395-399.

14 Neto R.B., Mello C.R., Rocha A.G., Sembenelli G., Sueiro F.R. \& Jark P.C. 2017. Plasmocitoma ósseo solitário em cães: Relato de três casos. ARS Veterinária. 33(1): 37-43.

15 Pargass I., Alissa B. \& Suepaul R. 2017. Oral Plasmacytoma in a Dog. Veterinary Science. 4(4): 1-5.

16 Platz S.J., Breuer W., Pfleghaar S., Minkus G. \& Hermanns W. 1999. Prognostic Value of Histopathological Grading in Canine Extramedullary Plasmacytomas. Veterinary Pathology. 36(1): 23-27.

17 Rusbridge C., Wheeler S.J., Lamb C.R., Page R.L., Carmichael S., Brearley M.J. \& Bjornson A.P. 1999. Vertebral Plasma Cell Tumors in 8 Dogs. Journal of Veterinary Internal Medicine. 13(2): 126-133.

18 Santana A.E., Seki M.C., Gama F.G.V. \& Sobreira M.F.R. 2008. Neoplasias do sangue e dos órgãos formadores de sangue. In: Daleck C.R., De Nardi A.B. \& Rodaski S. (Eds). Oncologia em Cães e Gatos. São Paulo: Roca, 512p.

19 Say F., Gürler D. \& Bülbül M. 2014. Solitary plasmacytoma of the femur: A case report. Journal of Experimental and Clinical Medicine. 31(4): 251-253.

20 Thumallapally N., Meshref A., Mousa M. \& Terjanian T. 2017. Solitary plasmacytoma: population-based analysis of survival trends and effect of various treatment modalities in the USA. BMC Cancer. 17(1): 1-11.

21 Vail D.M. 2013. Hematopoietic tumors section D Myeloma-Related Disorders. In: Withrow S.J. \& Vail D.M. (Eds). Small Animal Clinical Oncology. St. Louis: Saunders Elsevier, 768p.

22 von der Hoeh N.H., Tschoeke S.K., Gulow J., Voelker A., Siebolts U. \& Heyde C.H. 2014. Total spondylectomy for solitary bone plasmacytoma of the lumbar spine in young woman: a case report and review of literature. European Spine Journal. 23(1): 35-39. 